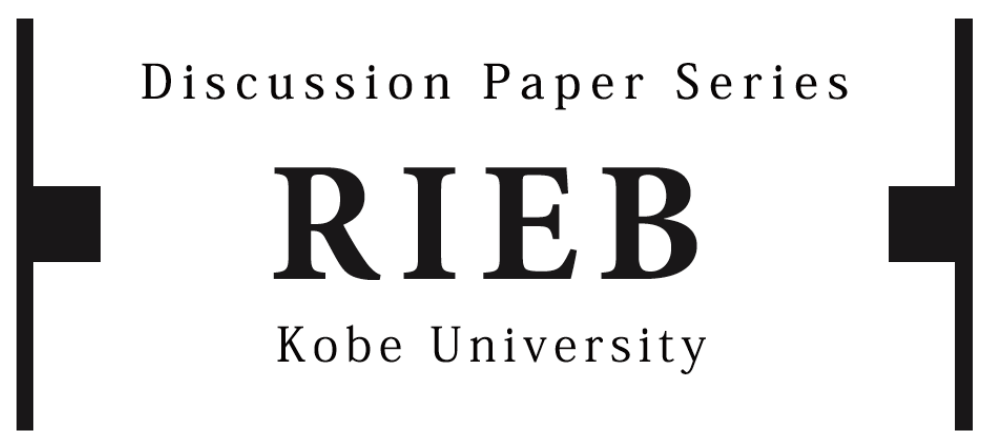

DP2011-04

\title{
Note on the Interpretation of Convergence Speed in the Dynamic Panel Model*
}

\author{
Masahiko SHIBAMOTO \\ Yoshiro TSUTSUI
}

January 20, 2011

* The Discussion Papers are a series of research papers in their draft form, circulated to encourage discussion and comment. Citation and use of such a paper should take account of its provisional character. In some cases, a written consent of the author may be required.

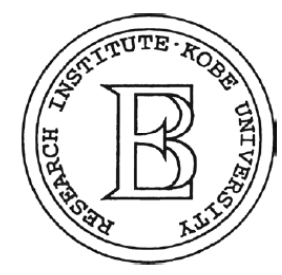

Research Institute for Economics and Business Administration

Kobe University 


\title{
Note on the Interpretation of Convergence Speed in the Dynamic Panel Model
}

\author{
MASAHIKO SHIBAMOTO ${ }^{a *}$ AND YOSHIRO TSUTSUI ${ }^{b}$ \\ ${ }^{a}$ Research Institute for Economics and Business Administration, Kobe University \\ ${ }^{b}$ Graduate School of Economics, Osaka University
}

January 20, 2011

\begin{abstract}
Studies using the dynamic panel regression approach have found the speed of income convergence among the world and regional economies to be high. For example, Lee et al. $(1997,1998)$ report the income convergence speed to be $30 \%$ per annum. This note argues that their estimates may be seriously overstated. Using a factor model, we show that the coefficient of the lagged income in their specification may not be the long-run convergence speed, but the adjustment speed of the short-run deviation from the long-run equilibrium path. We give an example of an empirical analysis, where the short-run adjustment speed is about $40 \%$.
\end{abstract}

JEL Classification: $\mathrm{O} 40$;

Keywords: convergence speed, dynamic panel regression, factor model

\footnotetext{
${ }^{*}$ Corresponding author: Research Institute for Economics and Business Administration, Kobe University, 2-1 Rokkodai, Nada, Kobe 657-8501, Japan. E-mail: shibamoto@rieb.kobe-u.ac.jp.
} 


\section{Introduction}

This note focuses on the interpretation of the speed of convergence with which the logarithm of per-capital real income tends to its steady-state value in the dynamic panel regression model. Researchers using the dynamic panel regression approach, e.g., Islam (1995, 1998), Lee et al. (1997, 1998), and Shioji (2001), argue that economies converge at a relatively high $\beta$-convergence speed as compared to the speed obtained in the analyses of conventional cross-sectional regression.

In this note, we argue that their estimates of the speed of $\beta$-convergence may be seriously overstated. Our point is that their calculations of the speed of $\beta$-convergence do not take into account the dynamics of a common component of the per capita real income, which may be highly persistent. Consequently, their estimates are not of the convergence speed in the long run, but the adjustment speed of the short-run deviation from the long-run equilibrium path.

\section{Controversies on the convergence speed obtained using dynamic panel regression}

We denote the logarithm of the per capita real income of the economy $i$ at time $t$ as $y_{i t}$. Let us start from the most basic model of dynamic panel regression:

$$
y_{i t}=\mu+b y_{i t-1}+\gamma^{\prime} \Theta_{t}+\zeta_{i t}, \text { for all } i=1, \cdots, N,
$$

where $\zeta_{i t}$ is an independent disturbance. $\mu$ is an economy-wide intercept that reflects the initial resource endowments. $\Theta_{t}$ is a vector of some time-specific effects (e.g., a linear time trend, an economy-wide average of real income, and a shock common to all economies) that reflects the technological progress across economies. ${ }^{1}$

This regression is a panel analog to the Barro regression and it is natural to interpret the coefficient of the lagged real income term as a function of the speed of convergence $\beta$ : namely, $b=\exp (-\beta)$. Many cross-sectional analyses employing the Barro regressions,

\footnotetext{
${ }^{1}$ For simplicity, we exclude some exogenous variables as the determinants of economic growth such as the savings rate, measures of investment in physical and human capital, and so on to focus on the interpretation of the convergence speed using the panel data approach.
} 
e.g., Barro (1991) and Barro and Sala-i-Martin (1992a,b), report that the estimate of $\beta$ is around $2 \%$ per annum.

Islam (1995) points out that allowing for intercept heterogeneity, i.e., $\mu_{i}$ instead of $\mu$ in equation (1), increases the estimate of the speed of convergence to $5 \%$ per annum. Indeed, if there is a positive correlation between these intercepts and the lagged real incomes, the conventional cross-section estimate of $b$ will be biased upward.

While Islam (1995) estimates the model where only the steady-state level of income is allowed to differ across economies and where the assumption that economies shared the same steady-state growth rate, given as $\gamma_{i}=\gamma$ for all $i=1, \cdots, N$ is made. Lee et al. (1998) criticize Islam (1995) for failing to allow for different common trends across the countries. $^{2}$ Their model is given as

$$
y_{i t}=\mu_{i}+b_{i} y_{i t-1}+\gamma_{i}^{\prime} \Theta_{t}+\zeta_{i t}, \text { for all } i=1, \cdots, N,
$$

which allows for the existence of non-parallel balanced growth paths. Lee et al. (1997, 1998) argue that homogeneity in the growth effects of convergence forces the estimate of $b$ toward 1, because it renders the panel estimator inconsistent. ${ }^{3}$ Based on this model, they report that the speed of $\beta$-convergence increases to around $30 \%$ per annum.

We support the generalization by Lee et al. (1997, 1998), since such a model is flexible to describe various economies. However, we cast doubt on the interpretation that the coefficient of the lagged dependent variable, $b_{i}$, represents the convergence speed in the long run, which is discussed in the next section.

\footnotetext{
${ }^{2}$ In response, Islam (1998) argues that Lee et al. $(1997,1998)$ are assessing an economically uninteresting form of convergence when they allow for trend differences. Durlauf et al. (2005) comment that "this debate is an excellent example of the issues of interpretation that are raised in moving between specific economic hypotheses and more general statistical models."

${ }^{3}$ We can understand that Lee et al. $(1997,1998)$ 's specification is appropriate by looking at the recent literature on the panel unit root test, e.g., Phillips and Sul (2003). Phillips and Sul (2003) argue that if the cress-sectional correlation for the error term is not accounted for, the estimates of the autoregressive coefficients will be biased. In order to control the cross-sectional correlation, the error term is given by a three-component model that contains a fixed effect $\left(\mu_{i}\right)$, a common factor $\left(\Theta_{t}\right)$, and a purely idiosyncratic factor $\left(\zeta_{t}\right)$. Then, it is standard practice to use a similar specification for equation (2) in the panel unit root test.
} 


\section{Interpretation of the key coefficient in dynamic panel re- gression in terms of a factor model}

The model described as equation (2) is similar to the common factor model by previous studies, e.g., Bai and Ng (2004), in that it allows for heterogeneous (non-parallel) growth paths. Based on the factor model, we will show that the interpretation of $b_{i}$ as the long-run convergence speed is inappropriate.

Bai and Ng (2004) develop the "Panel Analysis of Nonstationarity in Idiosyncratic and Common Components (PANIC)." The idea of PANIC is to decompose the observed panel data into the common and idiosyncratic components, and then test for stationarity in each component separately. Bai and Ng (2004) consider the following factor model:

$$
y_{i t}=v_{i}+\lambda_{i}^{\prime} F_{t}+e_{i t}
$$

where $F_{t}$ is the common component consisting of $r$ factors followed by the economies, $\lambda_{i}$ is a parameter vector that represents the different weights assigned to the common factors, and $e_{i t}$ for $i=1, \cdots, N$ is the idiosyncratic component with a zero mean and is orthogonal to the common factors $F_{t}$ and to itself.

Let us assume that each component, $e_{i t}, F_{t}$, follows the autoregressive regression model:

$$
\begin{aligned}
e_{i t} & =b_{i} e_{i t-1}+\zeta_{i t}, \text { for all } i=1, \cdots, N, \\
F_{t} & =\phi F_{t-1}+v_{t},
\end{aligned}
$$

where $\zeta_{i t}$ for all $i=1, \cdots, N$ and $v_{t}$ are the error terms with a zero mean. An $\zeta_{i t}$ shock propagates through the autocorrelation structure of equation (4).

From equations (3) and (4), we can derive

$$
\begin{aligned}
y_{i t} & =v_{i}+\lambda_{i}^{\prime} F_{t}+b_{i} e_{i t-1}+\zeta_{i t} \\
& =v_{i}\left(1-b_{i}\right)+b_{i} y_{i t-1}+\lambda_{i}^{\prime} F_{t}-b_{i} \lambda_{i}^{\prime} F_{t-1}+\zeta_{i t} \text {, for all } i=1, \cdots, N,
\end{aligned}
$$

which is observationally equivalent to the equation (2) with $\mu_{i}=v_{i}\left(1-b_{i}\right), \gamma_{i}=\left[\lambda_{i}^{\prime}-b_{i} \lambda_{i}^{\prime}\right]^{\prime}$, and $\Theta_{t}=\left[\begin{array}{ll}F_{t}^{\prime} & F_{t-1}^{\prime}\end{array}\right]^{\prime}$. As the result shows, the coefficient of the lagged real income $b$ in 
equation (6), which is the coefficient of the lagged income in equation (2), is nothing but the adjustment speed of the idiosyncratic component $e_{i t}$, as equation (4) shows.

If the idiosyncratic component is stationary, $b_{i}$ represents the adjustment speed of short-run deviation. Even if the idiosyncratic component is non-stationary, $b_{i}$ is biased as the long-run convergence speed, as long as the common factor is non-stationary. In other words, the interpretation of $b_{i}$ as the long-run convergence speed is valid only if the common factors $F_{t}$ do not exist or they are stationary processes, which seems improbable in most cases. $^{4}$

\section{Example}

Let us give an example of the adjustment speed of the short-run deviation. The example is an analysis using the per capita real income data for 46 Japanese prefectures, for the period 1955-1999. The estimation of the Bai and Ng (2004) model reveals that there exists one common component $F_{t}$, which is nonstationary, and idiosyncratic components $e_{i t}$ for $i=1, \cdots, 46$, which are all stationary (see Shibamoto et al., 2011). Thus, in this example, the estimate of $b_{i}$ in a type of equation (2) is nothing but the adjustment speed of the short-run deviation from the long-run path. In this case, the per capita incomes of the economies cointegrate with the common component with different long-run weights, which is characterized by $v_{i}+\lambda_{i} F_{t}{ }^{5}$ This implies that the economies have heterogeneous balanced growth paths. On the other hand, the idiosyncratic component, $e_{i t}$, which has only a transitory effect on the per capita real income, reflects the short-run deviation from the long-run path for the economy $i$.

Then, we estimate equation (4) to get the estimate of $b_{i}$ by ordinary least squares. ${ }^{6}$ The mean value of the estimated $b_{i}$ across prefectures was 0.67 , implying that the speed is about $40 \%(=-\log (0.67))$ per annum. This estimate is very large if we regard this as the long-run convergence speed, but it is a reasonable value for the adjustment speed of the short-run deviation, because short-run variations in economies, i.e., business cycles,

\footnotetext{
${ }^{4}$ Although we explain the case wherein $e_{i t}$ and $F_{t}$ follow the first-order autoregressive model in equations (4) and (5) for simplicity, the argument applies for any order of the autoregressive model.

${ }^{5}$ Bernard and Durlauf (1995)'s Definition 2.2 of "common trends in output" embodies this idea.

${ }^{6} \mathrm{We}$ add as explanatory variables four lags of the first difference of $\hat{e}_{i t}$ in equation (4) to remove the autocorrelation of the residuals.
} 
normally return to their former levels in several years. This figure is comparable to $30 \%$ of the "speed of $\beta$-convergence" reported by Lee et al. $(1997,1998)$, which suggests that the figure reported by them is not really the long-run convergence speed, but the adjustment speed in the short-run. ${ }^{7}$

\section{References}

Bai, Jushan, Serena Ng. 2004 "A PANIC Attack on Unit Roots and Cointegration", Econometrica, 72(4): 1127-1177.

Barro, Robert J., Xavier Sala-i-Martin. 1992a "Convergence", Journal of Political Economy, 100(2): 223-251.

Barro, Robert J., Xavier Sala-i-Martin. 1992b "Regional Growth and Migration: A JapanUnited States Comparison", Journal of the Japanese and International Economies, 6(4): $312-346$.

Barro, Robert J.. 1991 "Economic Growth in a Cross Section of Countries", Quarterly Journal of Economics, 106(2): 407-443.

Bernard, Andrew B., Steven N. Durlauf. 1995 "Convergence in International Output", Journal of Applied Econometrics, 10(2): 97-108.

Durlauf, Steven N., Paul A. Johnson, Jonathan R.W. Temple. 2005 "Growth Econometrics", In Philippe Aghion, Steven N. Durlauf eds. Handbook of Economic Growth, 1. North-Holland: 555-677.

Islam, Nazrul. 1995 "Growth Empirics: A Panel Data Approach", Quarterly Journal of Economics, 110(4): 1127-1170.

Islam, Nazrul. 1998 "Growth Empirics: A Panel Data Approach-A Reply", Quarterly Journal of Economics, 113(1): 325-329.

Lee, Kevin, M. Hashem Pesaran, Ronald Smith. 1997 "Growth and Convergence in MultiCountry Empirical Stochastic Solow Model", Journal of Applied Econometrics, 12(4): $357-392$.

\footnotetext{
${ }^{7}$ They admit that the interpretation of this value as the $\beta$-convergence speed is highly questionable.
} 
Lee, Kevin, M. Hashem Pesaran, Ronald Smith. 1998 "Growth Empirics: A Panel Data Approach-A Comment", Quarterly Journal of Economics, 113(1): 319-323.

Phillips, Peter C. B., Donggyu Sul. 2003 "Dynamic Panel Estimation and Homogeneity Testing under Cross Section Dependence", Econometrics Journal, 6(1): 217-259.

Shibamoto, Masahiko, Yoshiro Tsutsui, Chisako Yamane. 2011 "Understanding Regional Growth Dynamics in Japan: Panel Cointegration Approach Utilizing the PANIC Method". RIEB Discussion Paper Series No. 243, Kobe University.

Shioji, Etsuro. 2001 "Public Capital and Economic Growth: A Convergence Approach", Journal of Economic Growth, 6(3): 205-227. 